Sección Historia del Derecho Europeo 

Revista de Estudios Histórico-Jurídicos

[Sección historia del derecho europeo]

XL (Valparaíso, Chile, 2018)

[pp. 169 - 182]

\title{
Libertad RELIGIOSA Y DERECHO DE GENTES EN LA POLONIA TARDO MEDIEVAL: EL CASO DE PAWEL WLODKOWIC (PAulus Vladimiri)*
}

[Religious Freedom and the Law of Nations in Late Medieval Poland: the Case of Pawel Wlodkowic (Paulus Vladimiri)]

\author{
Bárbara DíAz KAYEL* \\ Universidad de los Andes, Chile
}

\begin{abstract}
RESUMEN
El presente artículo tiene como objetivo dar a conocer la obra del canonista polaco tardo-medieval Pawel Wlodkowic (Paulus Vladimiri), quien desarrolló el derecho de gentes, en particular los derechos de los pueblos no cristianos y la libertad religiosa. A partir de una breve presentación del autor y de su contexto histórico, el artículo se ocupará de las ideas de Wlodkowic en lo referente a la igualdad fundamental de todos los seres humanos, su libertad, en particular la libertad religiosa, y el derecho a la existencia de las naciones paganas. El artículo mostrará que la preocupación por la evangelización de los pueblos paganos es lo que potencia, en el autor, el estudio de los derechos y libertades de personas y comunidades y, con ello, desarrollo del ius gentium.
\end{abstract}

\section{Palabras Clave}

Pawel Wlodkowic (Paulus Vladimiri) - derecho de gentes - evangelización Concilio de Constanza.

\section{Abstract}

The purpose of this article is to spread the work of Pawel Wlodkowic (Paulus Vladimiri), Polish late-medieval canonist, who developed the law of the nations, especially the non-Christian nations and religious freedom. The article begins by introducing the author and his historical context, then Wlodkowic's ideas regarding the fundamental equality of all human beings, their freedom, especially religious freedom and the right of pagan nations to exist. This paper will show that evangelizing pagan nations are the author's concern, which drives him to study people and communities' rights and freedoms, and therewith the development of the ius gentium.

\section{KEYWORDS}

Pawel Wlodkowic (Paulus Vladimiri) - the law of the nations - evangelization Council of Constance.

Recibido el 26 de septiembre de 2017 y aceptado el 23 de mayo de 2018

* Bárbara Díaz es Profesora de la Universidad de los Andes, Chile. Este artículo fue elaborado gracias al Fondo de Ayuda a la Investigación (FAI) de la Universidad de los Andes. Álvaro del Portillo 12455 Las Condes. RM. bdiaz@uandes.cl. 


\section{INTRODUCCIÓN}

Es común que las historias del pensamiento político y jurídico se centren en el devenir de las ideas en Europa Occidental, considerando más tarde a Norteamérica, y que el espacio centroeuropeo y de Europa del Este quede en el olvido o despachado en unas pocas pinceladas. Es lo que ocurrió en el caso de la llamada "escuela de derecho de gentes de Cracovia", que se desarrolló en la Universidad de esa ciudad a finales del siglo XIV y durante buena parte del siglo XV. Fuera de Polonia es difícil encontrar referencias a esta escuela que, sin embargo, se revela por demás interesante en sus planteamientos, muy actualizada en las discusiones que se llevaban a cabo contemporáneamente en los centros académicos más prestigiosos de Occidente, y que buscó proveer soluciones jurídicas a problemas reales que se vivían en ese momento en Polonia y países vecinos. Al mismo tiempo, dichas soluciones no fueron solo circunstanciales, sino que engrosaron el incipiente derecho de gentes que se venía gestando desde los siglos anteriores por obra, especialmente, de los canonistas.

Este artículo pretende dar a conocer la obra del más reconocido de estos autores, Pawel Wlodkowic (Paulus Vladimiri), y se centrará en dos aspectos: la libertad religiosa y el derecho de gentes, ambos profundamente relacionados en su pensamiento.

El plan de este artículo es el siguiente: en primer lugar, esbozaré la biografía del autor, presentando el contexto polaco de su época y el Concilio de Constanza, lugar donde expuso sus principales ideas (I); discutiré sus ideas de igualdad fundamental de todos los seres humanos (II), de libertad y dominio (III), de libertad religiosa y tolerancia (IV) y el derecho a la existencia de las naciones paganas (V).

Pawel Wlodkowic se beneficia de todo el pensamiento medieval, en particular del siglo XII en adelante. La unidad de la naturaleza humana, junto con la diversidad de modos de concretarla culturalmente, están bien presentes en su pensamiento. Dicha unidad, junto con la afirmación de que todos los hombres son prójimos, lo lleva a afirmar la idea de un derecho de gentes común a cristianos y no cristianos; la diversidad, a defender la libertad religiosa y la tolerancia, y a buscar elementos jurídicos que las protejan. Concluiré que la preocupación evangelizadora fue el motivo que impulsó al autor a profundizar en los derechos y libertades de todos los seres humanos y al desarrollo del ius gentium (VI).

\section{Presentación del aUtor y CONTEXTO históRico}

La Edad Media es vista por muchos como una época en la que la violencia en la imposición de la fe era la regla general, y las guerras santas y las cruzadas un mandato considerado poco menos que divino. Sin embargo, aun cuando todo ello ocurrió, también hubo quienes defendieron la tolerancia religiosa, y promovieron la libertad para recibir la fe, actitud que, por otra parte, era la doctrina común enseñada por la Iglesia desde la época de los Padres. En esta ocasión, me referiré al caso de Pawel Wlodkowic, canonista polaco de finales de la Edad Media, a quien le tocó defender la libertad religiosa de los pueblos que vivían alrededor del reino de Polonia, frente a las incursiones violentas de los Caballeros Teutónicos. 
Su defensa de las posiciones polacas ante el Concilio de Constanza permitió que sus argumentos tuvieran eco en toda Europa.

A comienzos del siglo XV, Polonia se consolidaba como reino, extendiendo sus fronteras y uniéndose, por lazos matrimoniales, a la recién cristianizada Lituania. El rey Jagiello daría al reino un nuevo esplendor posicionándolo como interlocutor importante en el centro y este de Europa. En tal carácter, la expansión de la orden religioso-militar de los Caballeros Teutónicos sobre los territorios prusianos, al norte y este del territorio polaco, más allá de sus discutibles métodos de conversión, constituía una amenaza para el diseño geopolítico polaco. Polonia tenía amplias relaciones con las naciones de su entorno: el reino de Bohemia, el de Hungría, el principado de Moscú, el Imperio Germánico. Por otra parte, al norte y este era vecina de pueblos no cristianos: samogitios, mogoles y tártaros, entre otros.

Por tanto, Polonia fue una nación de frontera para la Cristiandad, y plenamente consciente de su papel. Esta condición definió estrategias políticas y religiosas, permitió contactos fructíferos con culturas orientales y contribuyó a la apertura del país a mundos distintos. Los pueblos del este poseían una rica tradición intercultural e interreligiosa, fruto de repetidas oleadas de invasiones, desplazamientos y contactos comerciales. Por ello, como afirma Dariusz Kolodziejczyk, eran más abiertos que los europeos occidentales, de cultura más homogénea ${ }^{1}$. Esta condición de apertura habría influido sobre Polonia, haciendo de ella un puente entre occidente y oriente.

El modo de llevar adelante la evangelización fue un asunto crucial en el reino. Los polacos optaron por un proceso pacífico, a cargo de las órdenes religiosas establecidas en el territorio. Por otra parte, los Caballeros Teutónicos (también llamados Crucíferos) que, una vez fracasadas las Cruzadas, habían puesto sus ojos en los territorios del Báltico, pretendían llevar a cabo la cristianización mediante conversiones forzadas y la colonización germánica de los territorios.

Los Caballeros Teutónicos habían nacido como una de las tantas órdenes religioso-militares producto de las Cruzadas. Terminadas estas, buscaron otros lugares donde actuar. Al menos dos veces por año, estos monjes armados organizaban reisen, expediciones armadas a las que invitaban a caballeros de toda Europa, entusiasmándolos con la idea de una cruzada contra los paganos ${ }^{2}$. Lo cierto es que estas expediciones tenían poco de evangelización y bastante de rapacidad, muerte y destrucción. En 1410 se produce la batalla de Grünwald (Tannenberg), donde los polacos infligen una gran derrota a los teutónicos, obligándolos a retirarse de sus posiciones bálticas.

Desde el punto de vista cultural, Polonia se estaba consolidando como estado. Para ello, procuraba aumentar el nivel académico tanto de su personal político como de los misioneros, y a ello contribuía la Universidad de Cracovia, renova-

1 KolodzIEJCZyK, Dariusz, Entre l'antemurale Christianitatis et la raison d'État. L'idée de Croisade en Pologne aux XVe et XVIe siècles, en: L'Europe centrale au seuil de la modernité : Mutations sociales, religieuses et culturelles. Autriche, Bohême, Hongrie et Pologne, fin du XIVe siècle - milieu du XVIe siècle. Actes colloque international de Fontrevaud (15-16 mai 2009), (Rennes, 2010), pp. 19-26.

${ }^{2}$ Chollet, Loïc, Croisade ou évangélisation?, en Ordines Militaires, 20 (2015), pp. 175-203. 
da por el rey, de ahí que sea conocida como Universidad Jagiellónica. Muchos estudiantes polacos se formaban en Italia, en especial como juristas y canonistas, y luego volvían como maestros a Cracovia, a la sazón capital del reino.

Fueron juristas destacados en Cracovia Stanislas Skarbirmierz, autor del célebre Sermo de Bellis Iustis, Andreas Laskary, miembro de la delegación polaca al concilio de Constanza, que pronunció un célebre sermón, y Pawel Wlodkowic.

Pawel Wlodkowic -también conocido por su nombre latinizado Paulus Vladimiri o Wladimiri- nació en Brudzenia en 1370 y murió en Cracovia en 1436. Estudió cánones en Praga y Padua y luego retornó a su patria para ser rector de Cracovia. El rey le asignó misiones diplomáticas de importancia, entre las cuales resalta el envío al concilio de Constanza para defender los intereses polacos frente a los embates de la Orden de los Caballeros Teutónicos.

A partir del siglo XII, los canonistas formados en las nuevas Universidades habían comenzado a desarrollar el ius gentium de un modo novedoso. Durante la época romana, este derecho era fundamentalmente privado, aplicado a las relaciones entre extranjeros, o entre romanos y extranjeros, en el ámbito territorial del Imperio. El pretor peregrino, encargado de dictar estas normas, se servía de los principios de equidad natural, potenciados por el universalismo de la filosofía estoica $^{3}$. Esta mayor universalidad permitió su aplicación a nuevos problemas que surgieron durante la Edad Media.

Los nuevos canonistas comenzaron a abordar cuestiones como el estatuto de los judíos y otros in f i e les, o la jurisdicción del papa en el ámbito político. Estudiosos como James Muldoon o Brian Tierney pusieron de manifiesto la importancia del aporte de los canonistas en la configuración del ius gentium ${ }^{4}$. El medievalista alemán Hermann Heimpel afirma la existencia de un r e c t á n g u lo r e f o $r$ m is t a , que abarcaba las ciudades de Cracovia, Praga, Heidelberg y Padua, cuyo centro principal eran las respectivas universidades, y cuyos representantes habrían tenido influencia fundamental en el concilio de Constanza 5 .

Inocencio IV (Sinibaldo da Fieschi), Enrique de Susa (el Ostiense ${ }^{6}$ ), Raymundo de Peñafort, Oldrado da Ponte, Juan Andrés y Francesco Zabarella se cuentan entre los canonistas más destacados. Asimismo, el Decretum Gratiani y las Decretales de Gregorio IX fueron obras de referencia fundamentales. Pawel Wlodkowic utiliza todas estas fuentes y reconoce de modo especial la influencia de Zabarella, su maestro en Padua. Zabarella había estudiado con Juan de Legnano, y luego enseñó en Padua y Florencia. Fue embajador del papa ante varias cortes europeas, y tuvo un papel importante en el concilio de Constanza.

${ }^{3}$ Cfr. Álvarez Londoño, Luis Fernando, Historia del derecho internacional público (Bogotá, 2006), p. 62.

${ }^{4}$ Vid. por ejemplo: Muldoon, James, The contribution of the medieval canon lawyers to the formation of International Law, en Traditio, 28 (1972); TIERNEY, Brian, The idea of natural rights. Studies on natural rights, natural law, and church law, 1150-1625 (Grand Rapids, Mich., 2005).

${ }^{5}$ Cit. en STump, Phillip, The Reforms of the Council of Constance (1414-1418) (Leiden, 1994), p. 14.

${ }^{6}$ Según los autores se le encuentra con diferente ortografía, con o sin H. Opté por escribirlo sin $\mathrm{H}$. 
El concilio de Constanza (1414-1418) fue convocado para poner fin al Cisma de Occidente -que dividía a la Iglesia europea desde hacía varias décadas-, para condenar ciertas herejías y acometer la reforma de la Iglesia. Además, se trataron otros temas como la licitud del tiranicidio o la unión con la iglesia ortodoxa, que interesaba también desde el punto de vista político porque los turcos amenazaban el este de Europa ${ }^{7}$. La condena a la hoguera de Juan Hus fue uno de los hechos más relevantes de este concilio, junto con la expansión del conciliarismo, postura que consideraba que el concilio ecuménico se encontraba por encima del papa. En Constanza se reunieron los principales políticos y académicos del momento: el emperador Segismundo, los académicos parisinos Jean Gerson y Pierre d'Ailly, el canonista Zabarella, el sabio bizantino Manuel Chrysoloras. En el ámbito del derecho internacional, este concilio pasa a la historia por ser la primera vez que se presentan ante un foro internacional todos los aspectos de las relaciones entre los pueblos cristianos y los no cristianos ${ }^{8}$.

$\mathrm{Al}$ anunciarse el concilio, el rey Jagiello consideró oportuno enviar una representación diplomática que hiciera valer los derechos de Polonia, Lituania y los pueblos recientemente convertidos, y expresara las opiniones polacas acerca de la evangelización y el tratamiento a los infieles. Así es como se formó la embajada que se dirige al Concilio, integrada, entre otros, por el rector de Cracovia Pawel Wlodkowic.

La mayor parte de los escritos que se conservan de este autor proceden de este período. En primer lugar, hay que mencionar el conocido como Sevientibus o De Potestate Pape et Imperatoris respectu Infidelibus, leído ante la nación germánica en 1415. Opinio Ostiensis es un escrito similar al anterior, pero distribuido a todos los participantes en el concilio. En él, Wlodkowic discute ciertas posturas del canonista Cardenal Ostiense. Más adelante aparece $A d$ aperiendam, en el que analiza la naturaleza y estatuto de la Orden Teutónica, y dos escritos en los que discute ciertos panfletos distribuidos por agentes de la Orden contra los polacos: Quoniam error e Iste tractatus.

\section{Naturaleza de loS INFIEles: TODOS LOS HOMBRES SON PRÓJIMOS}

En línea con la tradición cristiana, Wlodkowic considera que existe una igualdad fundamental entre todos los hombres. Los infieles no tienen una naturaleza diferente de la de los cristianos: se distinguen de ellos en que no poseen la fe.

${ }^{7}$ La amenaza turca tanto al mundo occidental como al Imperio Bizantino creó un clima favorable a la unión de las iglesias, aunque finalmente ello no se concretó. Polonia tuvo un papel importante en estas negociaciones.

${ }^{8}$ Cfr. Dufour, Alfred, Droit international et chrétienté: des origines espagnoles aux origines polonaises du droit international. Autour du sermon De bellis justis du canoniste polonais Stanislas de Skarbimierz (1360-1431), en Dupuy, Pierre-Marie y CHETAIL, Vincent (eds.), The Roots of International Law / Les fondements du droit international. Liber Amicorum Peter Haggenmacher (Brill on line Source, 2013), pp. 95-119, http://catalog.lib.ku.edu/cgi-bin/Pwebrecon.cgi?bbid=5348770, p. 119. 
En la Edad Media, el vocablo infiel designa una categoría jurídica, con una significación propia, no necesariamente despectiva. De acuerdo con Xavier Tubau, existen tres clases de infieles:

1. Los que dependen de facto y de iure de los cristianos. Son no cristianos que viven en territorios cristianos y bajo sus leyes.

2. Los que dependen de iure pero no de facto de los cristianos. Son no cristianos que viven en zonas que antes ocupaban los cristianos (por ejemplo, los musulmanes en el Cercano Oriente).

3. Los que no dependen ni de iure ni de facto de los cristianos, pues viven en lugares donde el cristianismo es ignorado?

Los canonistas diferían en cuanto a la condición de los infieles, en especial los de la tercera categoría. Mientras que Inocencio IV, que además de papa era gran canonista, consideraba que ellos tenían plena posesión de sus dominios, el Ostiense afirmaba que los habían perdido con el advenimiento de Cristo. Ambas opiniones fueron ampliamente discutidas y citadas durante los últimos siglos de la Edad Media.

El primer argumento que Wlodkowic debía defender era el de la común humanidad de cristianos e infieles, a fin de sacar las consecuencias naturales de ese hecho fundante. En Saevientibus, enfatiza que todos los seres humanos son proximi: "Proximi autem nostri secundum veritatem sunt tam fideles quam infideles indistincte" 10 . De aquí nace la necesidad de respetar a todo hombre por encima de su condición pecadora. Siguiendo a san Agustín afirma que "no recibimos a los pecadores en cuanto pecadores sino que, por ser hombres, les debemos humana consideración, perseguimos en ellos la iniquidad pero tenemos misericordia por su común naturaleza"11.

Citando a Inocencio IV, Wlodkowic afirma que todos los seres humanos son libres por naturaleza y, por tanto, capaces de dominio: los infieles pueden, lícitamente y sin pecado, tener dominio, posesiones y jurisdicción, porque estos han sido hechos no solo para los fieles sino para todas las criaturas racionales"12.

Para argumentar en favor de esta noción, se basa en la ley natural, y se apoya en san Pablo, que afirmaba que los gentiles, que no tenían ley, seguían la ley impresa en sus corazones: "pues cuando los gentiles, que no tienen ley, cumplen naturalmente prescripciones de la ley, sin tener ley, para sí mismos son ley, y asi muestran tener la realidad de esa ley escrita en su corazón, atestiguándolo su conciencia"13.

Durante los siglos XII y XIII, los juristas habían desarrollado la noción de dominio, que permitía explicar, en primer lugar, la libertad, y luego la existencia de la propiedad privada y de la autoridad política. Teólogos como Tomás de Aquino también la utilizaron, pues permitía comprender mejor las consecuencias

9 Tubau, Xavier, Canon Law in Juan Ginés de Sepúlveda's Democrates Secundus, en Bibliothèque d'Humanisme et de Renaissance, 73/2 (2011), pp. 25-277, esp. p. 270.

10 Wlodkowic, Pawel, Saevientibus, en Ehrlich, Ludwik, Works of Paul Wladimiri (a selection), (Varsovia, 1968), I, p. 59.

11 Ibíd., p. 202.

12 Ibíd, p. 13.

13 Rom, 2, 14-15. 
de la libertad no solo en la vida privada sino en la vida pública y en el gobierno. Wlodkowic continuará esta tradición.

Porque los seres humanos son libres, ellos tienen dominio sobre sí mismos, y esta es la base para su dominio privado o propiedad privada y para el dominio público o gobierno. Solo los sujetos racionales y libres tienen dominio. Los seres humanos pueden dominarse a sí mismos porque son racionales y capaces de reflexionar sobre sus acciones. "Por la virtud de la libre voluntad humana, el hombre fue dueño de sus actos y por tanto, pudo ser también dueño de cosas externas" 14 , afirma el Aquinate.

Del dominio de sí, los juristas pasan a considerar el dominio de cosas externas $y$, de este modo, justifican la propiedad privada. Inocencio IV escribió que la propiedad es un derecho de acuerdo a la ley natural de la razón: la ley civil proporciona solo las formas de acción a través de las cuales los reclamos de propiedad eran seguidos en juicio. Por tanto, los gobernantes no deberían despojar arbitrariamente a los ciudadanos de la propiedad: una ley en violación de un derecho natural es inválida salvo una justa causa ${ }^{15}$.

Inocencio también argumentaba que todos los pueblos, también los infieles, tenían derecho a adquirir propiedad y formar sus gobiernos. Dios había sujetado todas las cosas al dominio del ser humano como criatura racional. Al comienzo todo era común, pero la propiedad había sido introducida por la ocupación de las cosas in bonis nullius o por acuerdos ${ }^{16}$.

Los canonistas y juristas de la época habían estudiado esta cuestión y muchos de ellos creyeron que la división de propiedades era una ley de ius gentium, hecha necesaria por el pecado original. También aseguraba que la tierra estuviera bien cuidada y cultivada. La existencia del dominio privado era una prueba de racionalidad y, por tanto, de humanidad.

No obstante, este dominio fue duramente contestado por el Cardenal Enrique de Susa, el Ostiense, para el caso de los infieles. El Ostiense defendía que con el cristianismo los derechos quedaban ligados al bautismo, es decir a la gracia. Por tanto, los no bautizados podían ser despojados de sus bienes o de su jurisdicción sin remordimiento alguno por parte de los cristianos. Frente a esta opinión, Wlodkowic afirma en su escrito Opinio Ostiensis: "Esta es la opinión del Ostiense, que al advenimiento de Cristo toda jurisdicción, principado, honor y dominio fueron transferidos de los infieles a los fieles, y que hoy los infieles no tienen jurisdicción, ni poder o dominio, pues son incapaces de ello, como reclama esa opinión. Y aquellos infieles que no reconocen el Imperio romano deberian ser atacados, etc., y dice que esa guerra contra los infieles [...] es siempre justa y licita para los cristianos" ${ }^{17}$.

En el foro de Constanza, estas opiniones fueron foco de graves discusiones pues también las sostenía John Wyclif, cuyas doctrinas fueron condenadas en

\footnotetext{
${ }_{14}$ Tomás de Aquino, $S$ Th, 2a 2ae, q 66, 1, consultado en http://hjg.com.ar/sumat/cl c66.html.

${ }^{15}$ Cfr. Tierney, Brian, cit. (n. 4), p. 143.

16 Ibíd., p. 144.

17 Wlodkowic, Pawel, Opinio Ostiensis, en Ehrlich, Ludwik, Works, cit. (n. 10), I, p. 113.
} 
el concilio. Así pues, para Wlodkowic, sostener la postura contraria a Wyclif constituía un punto a favor de Polonia en dicha asamblea.

\section{LIBERTAD RELIGIOSA}

Wlodkowic afirma que todo hombre, como dignissima creaturarum mundi, es libre y que todo ser humano - no solo el cristiano- debe ser amado. De la convicción de la racionalidad y libertad de todos los seres humanos, surge para el autor la posibilidad de aceptar o no la fe que les es propuesta. Para ello, la predicación debe ser realizada sin violencia: "infideles non sunt ad fidem cogendi sed sanctis exortacionibus inducendi", afirma en Savientibus ${ }^{18}$. Para el polaco, no se debe obligar a los infieles a aceptar la fe, sino persuadirlos mediante santas exhortaciones. Afirma que una pretendida exhortación que va acompañada del despojo de propiedades y honores "non esset exortacio sed dura coactio" 19 .

Siguiendo la secular tradición cristiana, Wlodkowic piensa que las personas deben aceptar la fe libremente, después de buenas explicaciones y buenos ejemplos de vida cristiana. Por consiguiente, su rechazo no debería constituir motivo de guerra contra ellos. En este punto, se apoya en las conclusiones del IV concilio de Toledo respecto a la tolerancia a los judíos (replicado en el Decretum Gratiani así como en Gregorio IX): "Ergo non vi sed liberi arbitrii facultate ut convertantur suadendi sunt non potius impellendi" ${ }^{20}$.

Por contraste, considera que los actos de los Caballeros Teutónicos, al invadir a los paganos, exterminarlos por la fuerza y quitarles sus tierras, constituyen una violación de los principios cristianos.

En su escrito Ad Aperiendam, de 1416, el autor polaco califica a los Caballeros Teutónicos de herejes. Apoyándose en textos de Guido de Baysio -el Archidiácono-, quien distingue dos modos de herejía, una que atañe al conocimiento -error in ratione - y otra que consiste en la pertinacia de la voluntad, el maestro de Cracovia afirma que esta orden contiene un error que es contrario a la fe, pues esta, de acuerdo al Apóstol, obra por la caridad, mientras que la orden teutónica utiliza la violencia, el robo, la sedición y los homicidios. “Quién podría dudar que esta orden es una cruel herejía que excluye la fe de los apóstoles, que obra por la caridad, sin la cual es imposible agradar a Dios?21" Continúa explicando que este error va contra los preceptos del Decálogo: no matarás, no robarás. Por otra parte, el Apóstol dice que la ley se resume en una palabra: amarás a tu prójimo como a ti mismo, el que ama a su prójimo ha cumplido la ley. Y por eso esta herejía, que excluye el amor al prójimo, es contraria a toda ley y se rebela ante la divina majestad. Y al incluir violencia y robo, incluye codicia de poder y soberbia, que

18 WlodkowIC, Pawel, Saevientibus, (n. 10), p. 84.

19 Ibíd., p. 85.

20 Concilium Toletanum IV, canon 57. Consultado en http://www.cn-telma.fr/relmin/ extrait1051/ el 26-07-17.

${ }^{21}$ Cfr. Wlodkowic, Pawel, Ad Aperiendam, en Ehrlich, Ludwik, Works, cit. (n. 10), I, p. 197. 
es la madre de todos los vicios 22 . Esta idea de considerar la conducta de los Teutónicos como verdadera herejía va calando en su pensamiento, hasta que en sus escritos posteriores la denomina heresia prussiana.

Otro punto relacionado con la libertad para recibir la fe es la potestad del papa para enviar predicadores a territorios de infieles. Wlodkowic afirma que, si bien no se debe obligar a los infieles a aceptar la fe, sí pueden ser obligados a admitir predicadores, porque toda criatura racional está hecha para alabar a Dios. La no aceptación de los predicadores podría configurar causa justa de guerra, decidida por el papa: "Licet infideles ad fidem cogi non debeant et relinquendi sunt libero arbitrio quia sola Dei gracia in hac vocacione valet ut dicunt canones, papa tamen potest mandare infidelius quod admittant predicatores Evangelii in terris suis. Racio huius est quia omnis creatura racionabilis facta est ad Deum laudandum. Si ergo prohibent praedicare, peccant et ideo essent merito puniendi" ${ }^{23}$.

Como conclusión de este punto, podría afirmarse que en materia de libertad religiosa la postura de Wlodkowic es ambigua, como corresponde a un hombre que está a caballo entre lo medieval y lo moderno. A la vez que afirma que la fe es un acto de voluntad y que debe aceptarse libremente, considera que los infieles deben permitir a los predicadores en su territorio porque, ante todo, Dios debe ser adorado. En este punto, Wlodkowic confunde los planos natural y sobrenatural, al afirmar la necesidad de todo hombre de adorar al Dios verdadero y, por consiguiente, la licitud del castigo a quien no lo haga.

Es preciso recorrer el camino que va de Wlodkowic a Francisco de Vitoria, para ver, por un lado, cómo se puede argumentar a favor de la obligación de recibir predicadores desde un punto de vista puramente jurídico (derecho a la sociabilidad y comunicación), y cómo se pueden deslindar mejor las jurisdicciones temporal y espiritual ${ }^{24}$.

\section{TOlerancia RELigiosa}

La idea de tolerancia es otro aspecto clave en las ideas de Pawel Wlodkowic y, en general, de la Polonia bajo-medieval y moderna. A la hora de explicar las razones de esta actitud, que se manifestó en la aceptación de pobladores pertenecientes a otros cultos, en la no acepción de personas por razones religiosas, en las relaciones fluidas con pueblos vecinos pertenecientes a otras religiones, hay que apelar a ciertas circunstancias de orden histórico y cultural. Polonia creció como nación cristiana, rodeada de pueblos pertenecientes a otras confesiones cristianas (ortodoxos, herejes como los husitas de Bohemia), de musulmanes y de paganos.

Algunos de esos paganos vivían una actitud tolerante frente a los cristianos, como lo afirma el rey lituano Gediminas en carta al papa, en 1322: "No luchamos contra los cristianos para destruir la fe católica. Solamente nos resistimos ante las injurias causadas a nosotros, tal como lo hacen los reyes y principes cristianos; de

${ }^{22}$ Cfr. ibíd., p. 198.

${ }^{23}$ Wlodkowic, Pawel, Opinio Ostiensis, (n. 17), p. 124.

${ }^{24}$ Cfr. Vitoria, Francisco de, Relectio de Indis, 2do título legítimo $\$ 11$ y 12; 2do título ilegítimo $\$ 3$. 
hecho mantenemos a nuestro lado a los hermanos dominicos y franciscanos, a quienes hemos dado plena libertad de bautizar, instruir y administrar los sagrados ritos" 25 .

A diferencia de la expansión demográfica de Europa occidental, Polonia necesitó inmigrantes para cultivar sus tierras, artesanos y comerciantes. Por ello, una cantidad importante de extranjeros, algunos pertenecientes a otras religiones -entre ellos, un buen número de judíos- se asentó en su territorio, y se hizo necesario practicar con ellos la tolerancia ${ }^{26}$.

En el tratado Savientibus, Wlodkowic se pregunta si es lícito molestar a los infieles que quieren vivir pacíficamente entre los cristianos, y responde negativamente: "postquam infideles inter christianos volunt vivere pacifice, nulla molestia in personis et rebus est eis inferenda. [...] Peccat ergo dominus, si sine causa eos spoliet. Immo, nec papa debet eis bona auferre; quinimmo, debet quam diu potest eos tolerare. Et est ratio predictorum: ut per eorum commercium eos lucri Domino facere possemus" 27.

Para el cracoviense, la convivencia con los paganos podría ser una buena ocasión de darles a conocer la fe cristiana y facilitar su conversión, por tanto, era indispensable el buen trato, que se concretaba en la tolerancia religiosa. Wlodkowic se refiere en este punto a los judíos y sarracenos, para luego extrapolarlo a los ortodoxos y a los paganos de la zona oriental de Europa. De hecho, en el concilio de Constanza la delegación polaca trabajó intensamente tanto por la unión entre las iglesias del este y el oeste, como por el respeto de los derechos de los samogitios, en ese entonces en proceso de conversión ${ }^{28}$.

\section{LEGITIMIDAD DE LAS NACIONES PAGANAS}

Siguiendo a Inocencio IV, el maestro polaco sostiene la legitimidad de los reinos paganos, y la consiguiente ilegitimidad de la guerra contra ellos por el solo hecho de no ser cristianos.

En efecto, el dominio público hace referencia al poder de gobernar sobre un territorio y sobre otras personas, y es una derivación de la racionalidad y la libertad humanas $^{29}$. La capacidad de dominio es una característica humana, por tanto, no cabe aquí la distinción entre fieles e infieles.

En este punto, Pawel Wlodkowic realiza una distinción entre dominio privado y público: "Rex non est dominus bonorum et iurium Regni sed administrator. Alia enim sunt bona pertinencia ad personam Regis et alia pertinencia ad Regnum. [...] Unde [...] iurat Rex non alienare bona Regni quia non sunt sua" ${ }^{30}$.

${ }^{25}$ Carta de Gediminas al papa Juan XXII, 1322, en Lithuanian Quarterly Journal of Arts and Sciences, 15, (1969) 4, Www.LITUANUS.ORG.

${ }^{26}$ Cfr. Chollet, Loïc, Paul Vladimir (Pawel Wlodkowic) au Concile de Constance : une tradition de tolérance religieuse en Pologne et en Lituanie (Neuchâtel, 2010), p. 56 (pro manuscripto).

27 Wlodkowic, Pawel, Saevientibus, Ad primam, (n. 10), p. 9.

${ }^{28}$ Cfr. Lenfant, Jacques, Histoire du Concile de Constance (Amsterdam, 1727), p. 504.

${ }^{29}$ Ut supra, p. 6.

${ }^{30}$ Cfr. WŁodKowIC, Pawel, Ad videndum, en Ehrlich, Ludwik, Works, cit. (n. 10), III, p. 141-142. 
Dicha distinción es relevante para la época pues, con frecuencia, debido a las peculiaridades del sistema feudal, no quedaba clara la diferencia entre el dominio privado sobre unas tierras, y el gobierno o jurisdicción.

Los infieles tienen res publica rectamente fundadas, con gobernantes y leyes, y es ilegítimo despojar a esos pueblos de sus gobiernos. Las donaciones papales o imperiales de tierras de infieles y de sus gobiernos a cristianos, son inválidas, pues desconocen el derecho de los infieles a poseer y gobernarse. En el caso polaco, el emperador era responsable de algunas de esas donaciones, y acerca de ellas se pronuncia el maestro cracoviense: esas donaciones son nulas porque lo donado no pertenecía al donante, $y$ los bienes que pertenecen a otros no pueden ser donados ${ }^{31}$.

A partir del reconocimiento de las naciones paganas, Wlodkowic fundamenta la alianza entre reinos cristianos y paganos en caso de un peligro común. Dicha alianza tiene su base en la igualdad entre todas las naciones, y en la amistad entre todos los hombres.

En el caso polaco, los Caballeros Teutónicos habían acusado a Polonia de haberse aliado con paganos y cismáticos para luchar contra ellos en la batalla de Tannenberg, y por ello Wlodkowic debe argumentar a favor de su país, defendiendo, por una parte, la plena legitimidad de los reinos paganos, conformados de acuerdo al derecho natural y de gentes y, por otro, el derecho de alianza entre cristianos y paganos en virtud de la amistad entre todos los hombres. Para ello, se apoya en los canonistas Juan Andrés y Oldrado da Ponte ${ }^{32}$. Wlodkowic cambia el foco de atención, privilegiando la justicia de la guerra en lugar de la religión de los beligerantes ${ }^{33}$. Por otra parte, apoyado asimismo en la igualdad entre naciones de fieles y de infieles, sostiene que una nación cristiana puede auxiliar a una pagana si esta es agredida, incluso si lo es por parte de otros cristianos.

Un antecedente próximo de la postura de Wlodkowic es la de su coterráneo Skarbimierz, quien, en su sermón De Bello Iusto et Iniusto, pronunciado en los primeros años del siglo $\mathrm{XV}^{34}$, afirma la licitud del castigo a los cristianos que delinquen, por medio de otros cristianos, incluso aliados con infieles: "In bello iusto christianis iustam partem habentibus coniuncti, contra alios christianos malos pugnantes" 35 . En apoyo de su aserto, cita hechos bíblicos como el de los Macabeos, y afirma que, siendo la paz aquello a lo que todos aspiran, si esta es turbada es necesario usar todos los medios para recuperarla, por tanto, es lícito asociarse con los infieles para este fin ${ }^{36}$. La afirmación de la paz como fin de la comunidad política, de raíz agustiniana, tendrá luego mayor desarrollo en la obra de Francisco de Vitoria.

En los escritos de Pawel Wlodkowic se introduce un nuevo sujeto, la societas

31 WŁodKowıc, Pawel, Saevientibus, (n. 10), p. 58.

${ }^{32}$ Cfr. ibíd., pp. 75 ss.

33 Chollet, Loïc, Paul Vladimir, cit. (n. 26), p. 128.

${ }^{34} \mathrm{La}$ fecha del sermón es incierta pero, de todos modos, anterior a 1415.

35 Scarbirmiria, Stanislaw de, Sermones de sapientia selecti, en Chmielowska, Bozena (ed.), Corpus Philosophorum Polonorum (Varsovia, 2016), p. 61.

${ }^{36}$ Cfr. ibíd., p. 62. 
humanae $^{37}$. Esta comunidad no está aún bien delineada, pero es evidente que no se reduce a los reinos que reconocen al papa. Los cismáticos, los paganos, los ortodoxos tienen un lugar en esta proto-comunidad universal que se funda en la amistad. Wlodkowic, citando textos bíblicos y aristotélicos, afirma que la amistad entre cristianos e infieles es parte del derecho natural. La amistad, asimismo, justifica la alianza con los paganos: "la causa de aliados y amigos es una justa causa de guerra”.

Por otra parte, considera que la guerra, para ser justa, ha de ser permitida por una autoridad de carácter global, que, en el momento en que escribe Pawel, es solo la del papa y del concilio: este punto implica la existencia de una verdadera comunidad política, con autoridad real. Esta tiene poder para la resolución de conflictos y todas las naciones deben recurrir a ella para estar seguras de la legitimidad de sus demandas de justa guerra. El autor considera que deben prohibirse expresamente las decisiones unilaterales sobre la justicia del propio caso: tan solo la decisión de un tribunal competente autoriza el uso de la fuerza ${ }^{38}$. Por otra parte, el sumo pontífice también adquiere poder para castigar a los infieles en caso de desobediencia a la ley natural ${ }^{39}$.

Puede verse aquí una cierta confusión de poderes, porque el papa no es solo la cabeza de la Iglesia, sino también un juez en lo temporal: "Hoc autem certum teneo Romanum Pontificem tamquam vicarium Christi esse indubitatum iudicem omnium predictorum qui habet indicere bellum eciam incredulis Romanam ecclesiam non recognoscentibus quociens causa racionabilis hoc requirit" ${ }^{2}$.

Y más adelante explica: "Et tollendo sic ius societatis humane tollit eciam precepta moralia. Repugnat eciam iuri canonico et civili quod in alijs heresibus vix contingit, saltem ita clare, ac per hoc errat in moribus et in fide" 41 . El autor va descendiendo desde el ius societatis humane, o sea, el derecho de gentes, a la ley moral y luego a la ley positiva, sea civil o canónica. Los Crucíferos parten por desconocer el derecho de gentes y con él, desconocen preceptos morales fundamentales, que están contenidos en dicho ordenamiento jurídico, aunque también pertenecen al depósito de la fe. Por esto es que puede acusar de herético su comportamiento, al apartarse de la fe y las costumbres. Finalmente, la actuación de los caballeros viola leyes positivas, tanto de derecho civil como canónico. Es interesante cómo su razonamiento parte del derecho de gentes, pasando por las normas morales hasta la ley positiva. Indica que, en su pensamiento, la societas humane tenía la suficiente entidad como para considerarla fuente de derecho y no una mera forma de hablar. Por otra parte, le otorga un papel a los reyes y gobernantes como actores relevantes de la societas humane, pues deben colaborar en la extirpación de esta herejía y en la devolución de los territorios a sus dueños: "Preterea ipsorum enim est defendere rem publicam, presertim Ecclesiam et maxime fidem", afirma, citando

37 Vid. WLOdKowIC, Pawel, Quoniam error, in response to Johannes Frebach of Bamberg, en EHRLICH, Ludwik, Works, cit. (n. 10), II, p. 389.

38 Ibíd., p. 308.

39 Wlodkowic, Pawel, Opinio Ostiensis, cit. (n. 17), p. 124.

40 WlodKowic, Pawel, carta a Olesnicki, en Ehrlich, Ludwik, Works, cit. (n. 10), III, p. 223.

41 Wlodkowic, Pawel, Ad aperiendam, en Ehrlich, Ludwik, Works, cit. (n. 10), I, p. 202. 
a Isidoro de Sevilla. Ante todo les corresponde defender la res publica, en especial a la Iglesia, pues no se trata de personas privadas sino públicas ${ }^{42}$.

\section{CONCLUSIÓN}

La preocupación por la evangelización de los pueblos paganos vecinos a Polonia fue el motivo que impulsó a Pawel Wlodkowic y sus colegas de Cracovia a desarrollar los principios del derecho de gentes que los canonistas medievales estaban delineando desde el siglo XII, a la vez que a afirmar la libertad religiosa de todos los hombres.

Ambos aspectos tienen en común la idea de la igualdad radical de todos los hombres, independientemente de su raza o religión, y la constatación de que hay ciertos derechos que se derivan de la condición humana. Las libertades de creencia, de predicación y de aceptación de la fe propuesta, son consecuencia de la concepción antropológica del autor, que sigue en esto al Aquinate y a los canonistas medievales.

Por otro lado, la naturaleza social del hombre lo vuelca hacia la amistad, ya sea entre personas singulares o entre pueblos. Dicha amistad, cuya esencia es compartir bienes, permite emprender proyectos comunes como, por ejemplo, la defensa de la paz. A su vez, la amistad y la defensa de la paz hacen necesario el desarrollo del ius gentium, como derecho aplicable al conjunto de la societas humane. Este derecho regula la relación entre pueblos, sus alianzas y sus conflictos, en base a los principios de equidad natural.

El aporte de Pawel Wlodkowic y de sus colegas de Cracovia al desarrollo del derecho de gentes tendió pues a estrechar los contactos entre pueblos de cultura y religiones diferentes, proporcionando un marco jurídico para el desarrollo de relaciones justas entre ellos.

\section{FUENTES}

Concilium Toletanum IV, canon 57. Consultado en http://www.cn-telma.fr/relmin/ extrait1051/

GediminAS, carta al papa Juan XXII, 1322, en Lithuanian Quarterly Journal of Arts and Sciences, 15 (1969) 4, www.lituanus.org.

Scarbirmiria, Stanislaw de, Sermones de sapientia selecti, en ChmielowsKa, Bozena (ed.), Corpus Philosophorum Polonorum (Varsovia, 2016).

Tomás de Aquino, S Th, 2a 2ae, q 66, consultado en http://hjg.com.ar/sumat/cl c66.html.

Vitoria, Francisco de: Relectio de Indis (Corpus Hispanorum de Pace, CSIC, Madrid, 1989).

Wlodkowic, Pawel, Ad aperiendam, en Ehrlich, Ludwik, Works of Paul Wladimiri, I, pp. 144-271.

—Ad videndum, en EHrLICH, Ludwik, Works of Paul Wladimiri, III, pp. 91-202.

— carta a Olesnicki, en EHrLICH, Ludwik, Works of Paul Wladimiri, III, pp. 203-231.

${ }^{42}$ Ibíd., p. 222. 
—Opinio Ostiensis, en Ehrlich, Ludwik, Works of Paul Wladimiri, I, pp. 113-143.

-Quoniam error, in response to Johannes Frebach of Bamberg, en EHRLICH, Ludwik, Works of Paul Wladimiri, II, pp. 325-409.

—Saevientibus, en Ehruich, Ludwik, Works of Paul Wladimiri, I, pp. 2-112.

\section{BiBLIOGRAFÍA}

Álvarez Londoño, Luis Fernando, Historia del derecho internacional público (Bogotá, Pontificia Universidad Javeriana, Facultad de Ciencias Jurídicas 2006).

Chollet, Loïc, Croisade ou évangélisation?, en Ordines Militaires, 20 (2015), pp. 175-203.

-Paul Vladimir (Pawel Wlodkowic) au Concile de Constance : une tradition de tolérance religieuse en Pologne et en Lituanie (Neuchâtel, 2010) (pro manuscripto).

Dufour, Alfred, Droit international et chrétienté: des origines espagnoles aux origines polonaises du droit international. Autour du sermon De bellis justis du canoniste polonais Stanislas de Skarbimierz (1360-1431), en Dupuy, Pierre-Marie y Chetail, Vincent (eds.), The Roots of International Law / Les fondements du droit international. Liber Amicorum Peter Haggenmacher (Brill on line Source, 2013), pp. 95-119, http:// catalog.lib.ku.edu/cgi-bin/Pwebrecon.cgi?bbid=5348770.

EHrLICH, Ludwik, Works of Paul Wladimiri, "Introduction”, pp. X-LXVIII.

KolodZIEJCZYK, Dariusz, Entre l'antemurale Christianitatis et la raison d'État. L'idée de Croisade en Pologne aux XVe et XVIe siècles, en: L'Europe centrale au seuil de la modernité: Mutations sociales, religieuses et culturelles. Autriche, Bohême, Hongrie et Pologne, fin du XIVe siècle - milieu du XVIe siècle. Actes colloque international de Fontrevaud (15-16 mai 2009) (Rennes, 2010), pp. 19-26.

Lenfant, Jacques, Histoire du Concile de Constance (Amsterdam, Pierre Humbert, 1727).

Muldoon, James, The contribution of the medieval canon lawyers to the formation of International Law, en Traditio, 28 (1972), pp. 483-497.

Stump, Phillip, The Reforms of the Council of Constance (1414-1418) (Leiden, 1994).

TIERney, Brian, The idea of natural rights. Studies on natural rights, natural law, and church law, 1150-1625 (Grand Rapids, Mich., 2005).

Tubau, Xavier, Canon Law in Juan Ginés de Sepúlveda's Democrates Secundus, en Bibliothèque d'Humanisme et de Renaissance, 73/2 (2011), pp. 265-277. 